\section{(2) \\ BRAZIILIAN JOURNAL \\ OF MEDICAL AND BIOLOGICAL RESEARCH}

www.bjournal.com.br
ISSN 0100-879X

Volume 45 (3) 179-290 March 2012

BIOMIEDICAL SCIENCES

AND

CLINICAL INVESTIGATION

Braz J Med Biol Res, March 2012, Volume 45(3) 216-221

doi: $10.1590 / \mathrm{S} 0100-879 X 2012007500028$

Alternative complement pathway and factor B activities in rats with altered blood levels of thyroid hormone

C.S. Bitencourt, C.G. Duarte, A.E.C.S. Azzolini and A.I. Assis-Pandochi

The Brazilian Journal of Medical and Biological Research is partially financed by

\section{Q QNPPq}

Ministério da Ciência e Tecnologia

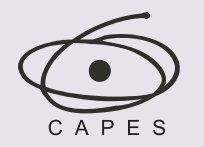

Ministério da Educação

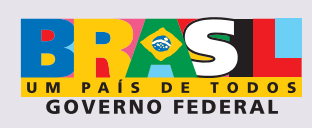

DTFAPESP

Institutional Sponsors

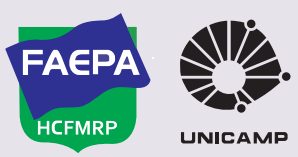

$\oplus$ SHIMADzu

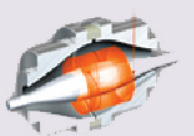

UNICAMP

1D Associaçäo Explore High - Performance MS Orbitrap Technology In Proteomics \& Metabolomics
SciE/O
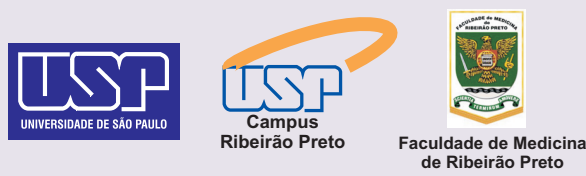
analitica $\underset{\text { analiticaweb.com.br }}{\text { Thermo }}$ S I NTIFIC 


\title{
Alternative complement pathway and factor $B$ activities in rats with altered blood levels of thyroid hormone
}

\author{
C.S. Bitencourt ${ }^{1}$, C.G. Duarte ${ }^{2}$, A.E.C.S. Azzolini² and A.I. Assis-Pandochi² \\ ${ }^{1}$ Departamento de Análises Clínicas, Toxicológicas e Bromatológicas, \\ Faculdade de Ciências Farmacêuticas de Ribeirão Preto, Universidade de São Paulo, Ribeirão Preto, SP, Brasil \\ 2Departamento de Física e Química, Faculdade de Ciências Farmacêuticas de Ribeirão Preto, \\ Universidade de São Paulo, Ribeirão Preto, SP, Brasil
}

\begin{abstract}
Evaluating the activity of the complement system under conditions of altered thyroid hormone levels might help elucidate the role of complement in triggering autoimmune processes. Here, we investigated alternative pathway (AP) activity in male Wistar rats $(180 \pm 10 \mathrm{~g})$ after altering their thyroid hormone levels by treatment with triiodothyronine (T3), propylthiouracil (PTU) or thyroidectomy. T3 and thyroxine (T4) levels were determined by chemiluminescence assays. Hemolytic assays were performed to evaluate the lytic activity of the AP. Factor B activity was evaluated using factor B-deficient serum. An anti-human factor B antibody was used to measure factor B levels in serum by radial immunodiffusion. T3 measurements in thyroidectomized animals or animals treated with PTU demonstrated a significant reduction in hormone levels compared to control. The results showed a reduction in AP lytic activity in rats treated with increasing amounts of $\mathrm{T} 3(1,10$, or $50 \mu \mathrm{g})$. Factor $\mathrm{B}$ activity was also decreased in the sera of hyperthyroid rats treated with 1 to $50 \mu \mathrm{g} \mathrm{T3}$. Additionally, treating rats with $25 \mu \mathrm{g}$ T3 significantly increased factor $B$ levels in their sera $(P<0.01)$. In contrast, increased factor B concentration and activity $(32 \%)$ were observed in hypothyroid rats. We conclude that alterations in thyroid hormone levels affect the activity of the AP and factor $B$, which may in turn affect the roles of $\mathrm{AP}$ and factor $\mathrm{B}$ in antibody production.
\end{abstract}

Key words:Thyroid hormone; Complement system; Alternative complement pathway; Factor B; T3; T4

\section{Introduction}

Complement consists of a group of serum and membrane proteins that protect the organism against pathogens and modified-self components, functioning as a dangersensing and transmission system (1) in innate and adaptive immune responses. Complement activation through the classical (CP), lectin or alternative (AP) pathways converges at the formation of $\mathrm{C} 3$ convertase, leading to the cleavage and activation of the $\mathrm{C} 3$ component. The events following this activation culminate in the assembly of the membrane attack complex (MAC), which disrupts the membrane of the target cell and can lead to cell lysis (2). The fragments generated during the activation process have important biological functions, including facilitation of phagocytosis, clearance of immunocomplexes, inflammation, the immune response, and tissue homeostasis $(3,4)$. Complement is an important link between innate and adaptive immunity, regulating both $B$ and $T$ cell responses by interacting with cell surface receptors. It is well known that complement fragments function in antibody production by activating naive $B$ cells, promoting the survival of B cells in germinal centers and functioning in the negative selection and maturation of self-reactive B cells (4).

Previous studies have indicated that there is a connection between the immune system and the hormones that regulate thyroid function (thyroid-stimulating hormone and thyrotropin-releasing hormone) (4-6). Additionally, the pathology of some thyroid diseases includes autoimmune processes (7). Hashimoto's thyroiditis results from the body mistakenly recognizing normal thyroid cells as foreign tissue and generating auto-antibodies against these cells. In Graves' disease, an autoimmune hyperthyroidism, the body produces auto-antibodies that stimulate and attack the

Correspondence: C.S. Bitencourt, Departamento de Análises Clínicas, Toxicológicas e Bromatológicas, Faculdade de Ciências Farmacêuticas de Ribeirão Preto, USP, Av. do Café, s/n, 14040-903 Ribeirão Preto, SP, Brasil. E-mail: claubitencourt@yahoo.com

Received May 31, 2011. Accepted February 7, 2012. Available online March 2, 2012. Published March 19, 2012. 
thyroid, causing the gland to grow and overproduce thyroid hormones (8). The activation of the complement system (CS) in these autoimmune processes has been described. Deposition of the MAC occurs in thyroid cells in Graves' and Hashimoto's diseases. The altered expression of complement membrane regulators (CD46, CD55, and CD59) can affect the damage produced by complement fixation in these cells (9). Oleesky et al. (10) showed that plasma levels of C9 are increased in Graves' disease and that treatment with anti-thyroid drugs decreases these levels. In a study of C6-deficient rabbits, it was suggested that the MAC is necessary for the development of fully expressed, severe experimental autoimmune thyroiditis and could be related to the pathogenesis of the disease (11).

The possible connection between alterations in thyroid hormone levels, complement proteins and the events of the immune response that trigger autoimmune processes deserves further investigation. Studies evaluating complement activity in both normal physiological conditions and under conditions of altered levels of thyroid hormones might further our understanding of the role played by the CS in triggering autoimmune processes. Antibody production against self components is one characteristic of these processes. Since the CS participates in antigen trapping within germinal centers and regulates multiple stages of the $B$ cell response (12), it is possible that the effects of thyroid hormones on the CS might indirectly affect antibody production and the onset of autoimmune diseases.

We observed that inducing hypothyroidism in rats by treatment with propylthiouracil (PTU) or by thyroidectomy increases the production of anti-sheep red blood cell antibodies (13) and that treating rats with triiodothyronine (T3) decreases antibody production (14). An increase in AP lytic activity is observed in hypothyroidism, suggesting a relationship between complement and low levels of thyroid hormones (15). Additionally, it was shown that a deficiency in C4b-binding protein does not affect the development of systemic lupus erythematosus (16). The authors of the cited study suggested that the alternative pathway drives complement-dependent renal injury and indicated that this pathway may be related to the progression of autoimmune diseases. In light of this information, we sought to examine AP activity in rats suffering from hyperthyroidism induced by treatment with T3. In addition, as AP activity was altered, factor B activity was also evaluated in both hyperthyroid rats (treated with T3) and in rats rendered hypothyroid by PTU or thyroidectomy.

\section{Material and Methods}

\section{Animals and treatment}

The animal breeding house of the Faculty of Pharmaceutical Sciences of Ribeirão Preto, University of São Paulo, supplied specific pathogen-free, young adult male Wistar rats weighing $180 \pm 10 \mathrm{~g}$. All treatment groups were main- tained under identical conditions. During treatment, animals received food and water ad libitum. Three different strategies to alter the thyroid hormones in rats were used.

The first group was treated with T3 from Purifarma ${ }^{\circledR}$ (Brazil). T3 was administered in a suspension consisting of $0.5 \mathrm{~g}$ carboxymethylcellulose (CMC), $0.18 \mathrm{~g}$ ethyl 4-hydroxybenzoate, $0.02 \mathrm{~g}$ propyl 4-hydroxybenzoate, and water in a final volume of $100 \mathrm{~mL}$. Rats were divided into experimental and control groups and received $1 \mathrm{~mL}$ T3 $(1.0$ to $50 \mu \mathrm{g}$ ) or $1 \mathrm{~mL}$ CMC suspension, respectively, by daily gavage for 7 or 12 days.

To obtain rats with low levels of thyroid hormones, PTU tablets from Biolab-Searle ${ }^{\circledR}$ (Brazil) were powdered and resuspended in water. Two milliliters of suspension (5 mg.200 g body weight ${ }^{-1} \cdot$ day $^{-1}$ ) or water (controls) was administered by gavage at timed intervals $(8,16$, and 30 days) to groups of approximately 8 rats each.

For thyroidectomy, adult rats weighing $180 \mathrm{~g}$ were anesthetized with an ip injection of $2.5 \%$ tribromoethanol in sterile saline solution ( $1 \mathrm{~mL} / 200 \mathrm{~g}$ weight). Standard procedures were used for thyroidectomy. Briefly, a midline skin incision was made along the length of the neck. The underlying tissues were removed, and the salivary glands were retracted laterally. The two halves of the sternohyoid muscle were separated and retracted laterally. The thyroid muscle was separated from the lobes of the thyroid gland and retracted along with the sternohyoid muscle. A midline cut was made in the isthmus, and the thyroid glands were excised bilaterally. Extreme care was taken not to damage the laryngeal nerve. Sham (euthyroid/control)-operated animals underwent the same surgical procedures without removal of the thyroid gland. Rats were used for experimentation 16 days after surgery.

In all procedures, the rats were euthanized according to criteria approved by the Ethics Committee for the Use of Animals (CEUA) of the Ribeirão Preto Campus, University of São Paulo (protocol No. 05.1.1160.53.9) $24 \mathrm{~h}$ after the end of each treatment and after $12 \mathrm{~h}$ of fasting. Blood samples were allowed to clot at room temperature for $1 \mathrm{~h}$. Aliquoted serum was stored at $-70^{\circ} \mathrm{C}$ until analysis.

\section{Determination of serum concentrations of thyroid hormones}

The concentrations of thyroid hormones [total T3 and total thyroxine (T4)] were measured using a competitive immunoassay with an enhanced chemiluminescence-end point (Immulite model 1000, DPC, USA). The Immulite analyzer, an instrument for solid-phase, two-site chemiluminescent assay (DPC), was used for hormone measurement. Assay sensitivities were $>1 \mu \mathrm{g} / \mathrm{dL}$.

\section{Evaluation of complement AP activity}

A hemolytic assay measuring the kinetics of lysis $(17,18)$ was performed to evaluate AP lytic activity. This method is based on the determination of the time required for serum to 
lyse $50 \%$ of an erythrocyte suspension $\left(t_{1 / 2}\right)$ under standard conditions. Triethanolamine (TEA) buffer $(20 \mathrm{mM})$ containing $0.15 \mathrm{M} \mathrm{NaCl}, 0.8 \mathrm{mM}$ azide, $8 \mathrm{mM}$ ethyleneglycol-bis( $\beta$-aminoethyl ether) N,N,N',N'-tetraacetic acid and $2 \mathrm{mM}$ magnesium (TEA/EGTA/Mg ${ }^{2+}$ ), $\mathrm{pH} 7.2$, was used for the assays. Rabbit erythrocytes were washed twice with TEA/ EGTA/Mg ${ }^{2+}$, and cell suspensions were standardized at an absorbance of $700 \mathrm{~nm}$ (approximately $10 \%$ erythrocytes). The rabbit erythrocyte suspension $(100 \mu \mathrm{L})$ was added to $200 \mu \mathrm{L}$ of test serum diluted in TEA/EGTA/Mg ${ }^{2+}$, and the mixture was subsequently incubated at $37^{\circ} \mathrm{C}$ to measure the kinetics of lysis.

\section{Evaluation of factor B activity}

Rat serum depleted of factor $B(R B)$ was prepared $(19,20)$ by heating a pool of sera at exactly $56^{\circ} \mathrm{C}$. Every $30 \mathrm{~s}, 60 \mu \mathrm{L}$ serum was removed and transferred to tubes containing TEA-EGTA-Mg ${ }^{2+}$ and kept on ice. Subsequently, $200 \mu \mathrm{L}$ of the rabbit erythrocyte suspension was added, and the mixture was incubated at $37^{\circ} \mathrm{C}$ for $30 \mathrm{~min}$. Cold PBS was added to stop the reaction, and the samples were then centrifuged for $10 \mathrm{~min}$. The absorbance of the solution at $412 \mathrm{~nm}$ was measured, and the percent lysis was calculated in reference to the lysis of erythrocytes in water (set to $100 \%$ ). The percent lysis was used to determine the residual AP activity.

The residual AP activity was evaluated to determine the time necessary to selectively inactivate factor B. RB was used to evaluate factor $B$ activity in the serum of experimental and control animals using a modified Mayer's method (21). Briefly, RB $(60 \mu \mathrm{L})$ was added to $300 \mu \mathrm{L}$ of test serum diluted 1:5 in TEA-EGTA-Mg ${ }^{2+}$. Samples were subsequently incubated with $200 \mu \mathrm{L}$ rabbit erythrocyte suspension for $30 \mathrm{~min}$ at $37^{\circ} \mathrm{C}$. After incubation, $300 \mu \mathrm{L}$ cold PBS was added, the samples were centrifuged and the absorbance of the supernatants was measured at $412 \mathrm{~nm}$. The absorbance of cell supernatants lysed in water $(100 \%$ lysis) or in RB without the addition of test serum ( $0 \%$ lysis) was measured as control.

\section{Determination of the relative concentration of factor $B$}

The relative concentration of factor $B$ was determined by radial immunodiffusion (22) using rabbit anti-human factor $B$ (Calbiochem, USA), which cross-reacts with rat factor $B$. The diameters of the precipitation halos were measured, and the values were expressed as a percentage of the halo diameter obtained from a pool of control rat sera.

\section{Statistical analysis}

Results for the control and treated animals were compared by the Mann-Whitney test using the GraphPad Prism software version 3.0 for Windows (GraphPad Software, USA) (23). P values < 0.05 were considered to be statistically significant.

\section{Results}

As expected, treating rats with $\mathrm{T} 3(25 \mu \mathrm{g})$ for 12 days (Figure 1A) increased the serum level of this hormone. The levels of T3 in the sera of both PTU-treated and control animals are reported in Figure 1B, which shows a significant decrease in T3 as a consequence of PTU treatment. The serum concentration of T4 was also measured in T3-treated rats; however, we were unable to detect T4 with the method employed in this study (sensitivity $>1 \mu \mathrm{g} /$ $\mathrm{dL}$ ). The AP lytic activity in the serum from rats treated with T3 was decreased (increased $t_{1 / 2}$ values) compared to control (Figure 1C). A range of T3 doses ( 0.15 to 50 $\mu \mathrm{g}$ ) was evaluated and showed a dose-dependent effect (data not shown). Treating rats with PTU for 16 days led
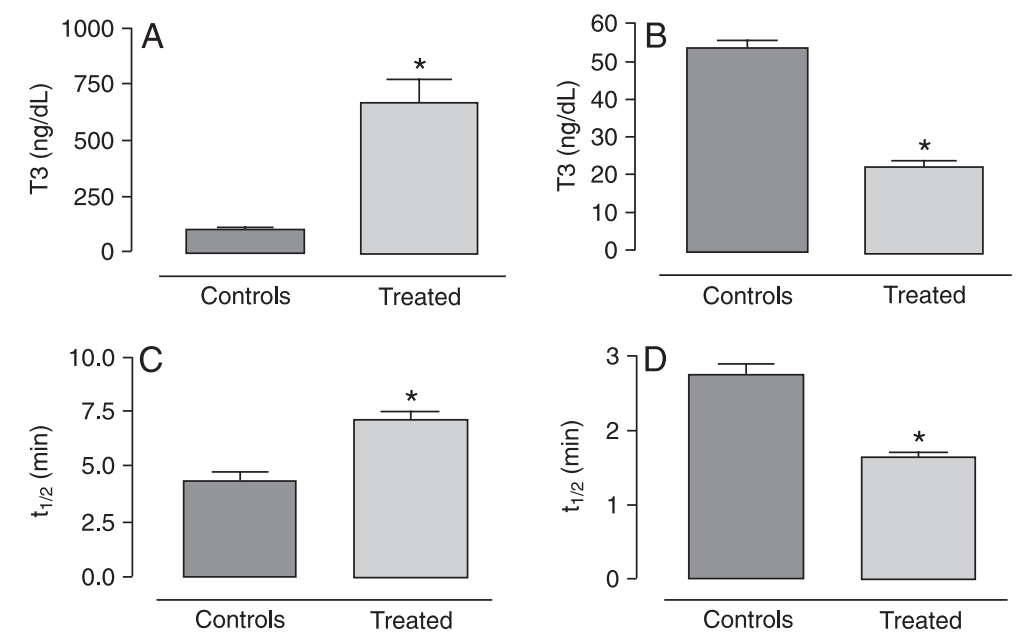

Figure 1. Treatment with triiodothyronine (T3) or propylthiouracil (PTU) alters the lytic activity of the alternative pathway. $A$, T3 levels detected in the sera of rats treated with either carboxymethylcellulose (CMC; controls) or $25 \mu \mathrm{g}$ T3 suspension for 12 days. Each column indicates the mean \pm SEM obtained for three independent experiments at each time $(\mathrm{N}=8) ;{ }^{*} \mathrm{P}=0.0043$ compared to rats treated with CMC (controls; Mann-Whitney test). $B$, Effect of PTU treatment on the serum levels of T3 in rats treated with water (controls) or with $5 \mathrm{mg}$ PTU suspension for 16 days. Each column indicates the mean \pm SEM obtained for three independent experiments at each time $(\mathrm{N}=10)$; ${ }^{*} \mathrm{P}=0.0001$ compared to rats that received water (controls; Mann-Whitney test). C, Effect of T3 treatment on AP lytic activity $\left(t_{1 / 2}\right)$. Rats were treated with either CMC (controls) or $25 \mu \mathrm{g}$ T3 suspension for 12 days. Each column indicates the mean \pm SEM obtained from $t_{1 / 2}$ values $(N=8)$; ${ }^{*} \mathrm{P}=0.0019$ compared to rats treated with CMC (controls; Mann-Whitney test). $D$, Effect of PTU treatment on AP lytic activity. Rats were treated with water or $5 \mathrm{mg}$ PTU suspension for 16 days. Each column indicates the mean \pm SEM obtained from $t_{1 / 2}$ values $(N=10)$; ${ }^{*} P=0.0286$ compared to rats treated with $C M C$ (controls; Mann-Whitney test). 
to a significant increase in AP lytic activity (decreased $t_{1 / 2}$ values, Figure 1D), corroborating a previous report (15). A range of PTU doses ( 1 to $25 \mathrm{mg} \cdot 200 \mathrm{~g}_{\text {body weight }}{ }^{-1} \cdot$ day $^{-1}$ ) was evaluated, showing that this effect was dependent on both the dose and the treatment period (data not shown). Similarly, T3 levels in thyroidectomized rats (Table 1) decreased over 4-fold compared to sham-operated animals, while AP lytic activity increased $30 \%$.

\section{Evaluation of factor $B$ activity}

Prior to the experiments, RB was prepared as described in Material and Methods. RB is a serum depleted of factor $B$ by heating. As shown in Figure 2A, heating the serum for $30 \mathrm{~s}$ resulted in a hemolysis rate of $65 \%$, followed by a reduction of $30 \%$ after 30 additional seconds of heating, confirming that AP lytic activity decreased as heating times increased. Based on this result, we chose an incubation time of $180 \mathrm{~s}$ to demonstrate that the heating process was able to inactivate factor $B$. To restore factor $B$ activity to the inactivated samples, we added purified human factor B at concentrations below, above and equivalent to the factor $\mathrm{B}$ concentration in human serum. The AP Iytic activity was restored by the addition of purified human factor $B$, showing that we efficiently produced $\mathrm{RB}$ samples by heating the serum to $56^{\circ} \mathrm{C}$ for $180 \mathrm{~s}$ (Figure 2B). Following this step, factor $B$ activity was evaluated in sera from rats treated with thyroidectomy, PTU or T3. As observed in Figure 3, a reduction in the functional activity of factor $B$ was observed in rats treated with increasing concentrations of T3 for 7 days (Figure 3A) or with $25 \mu \mathrm{g}$ T3 for 12 days (Figure 3B).

Treating rats with $\mathrm{PTU}$ increased factor $\mathrm{B}$ activity (Figure 4A). A similar result was also observed in thyroidectomized animals when compared to sham-operated controls (Table 2). Treating rats with PTU to induce hypothyroidism increased the serum concentration of factor $B$ as indicated by a specific antibody using radial immunodiffusion (Figure 4B).

\section{Discussion}

Previous results from our laboratory have shown that PTU-induced hypothyroidism in rats increases the production of antibodies against sheep red blood cells (13) while hy-

Table 1. Serum levels of triiodothyronine (T3) and alternative pathway lytic activity $\left(\mathrm{t}_{1 / 2}\right)$ in thyroidectomized $(\mathrm{Tx})$ and shamoperated (SO) rats.

\begin{tabular}{lcc}
\hline & T3 $(\mathrm{ng} / \mathrm{dL})$ & $\mathrm{t}_{1 / 2}(\min )$ \\
\hline Tx & $15.63 \pm 4.93(\mathrm{~N}=10)$ & $1.288 \pm 0.32(\mathrm{~N}=12)$ \\
SO & $65.51 \pm 8.14(\mathrm{~N}=9)$ & $1.865 \pm 0.39(\mathrm{~N}=10)$ \\
\hline
\end{tabular}

Data are reported as the means \pm SD for three independent experiments.
A

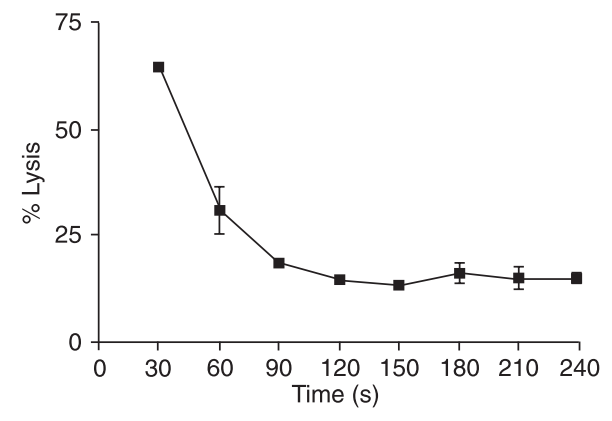

B

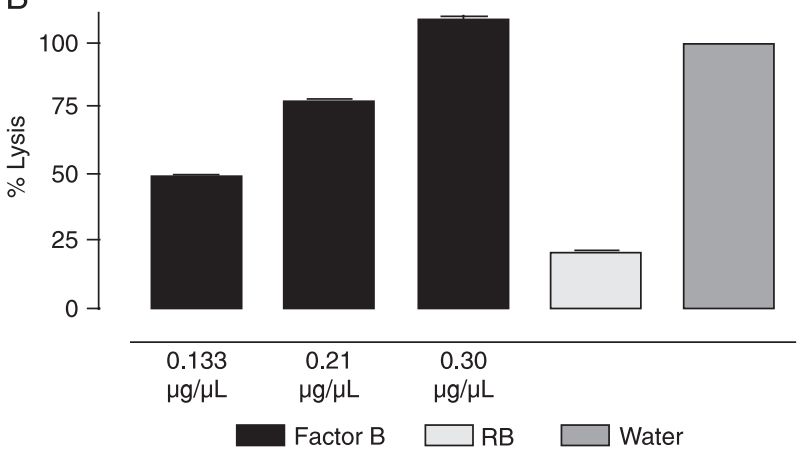

Figure 2. Production and evaluation of rat sera depleted of factor $\mathrm{B}(\mathrm{RB})$. $A$, The inactivation of rat complement in serum was performed at $56^{\circ} \mathrm{C}$. The alternative pathway (AP) lytic activity of a pool of normal rat sera decreased with increasing heating time (s). The points of the curve correspond to the mean \pm SD values from duplicate experiments. $B, A P$ lytic activity of a pool of normal rat serum inactivated at $56^{\circ} \mathrm{C}(\mathrm{RB})$ and incubated with different concentrations of purified human factor $\mathrm{B}$ to restore the lytic activity. Values obtained for three independent experiments at each time. The lysis of sheep red blood cells in water was used as a control (100\% lysis).

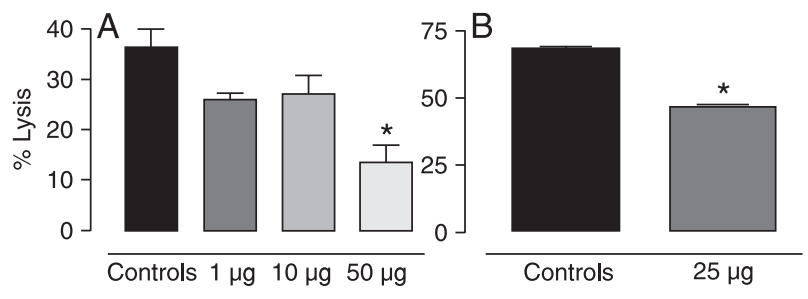

Figure 3. Treatment with triiodothyronine (T3) alters the functional levels of factor B. A, Rats were treated with 1,10 or 50 $\mu \mathrm{g}$ T3 for 7 days, and factor B activity was evaluated using rat serum depleted of factor $B(R B)$. The controls received carboxymethylcellulose (CMC). Each column indicates the mean \pm SD of hemolysis (\%) by RB added to sera from controls or experimental rats $(\mathrm{N}=8)$, obtained for three independent experiments at each time; * $\mathrm{P}<0.01$ compared to rats treated with $\mathrm{CMC}$ (controls; ANOVA with the Dunnett test for multiple comparisons). B, Rats were treated with $25 \mu \mathrm{g}$ T3 for 12 days and factor B activity was evaluated using RB. The controls received CMC. Each column indicates the mean \pm SD of hemolysis (\%) by RB added to sera from controls or experimental rats $(\mathrm{N}=8)$, obtained for three independent experiments at each time; ${ }^{*} P<0.0001$ compared to rats treated with CMC (controls; Mann-Whitney test). 
Table 2. Relative factor B activity in thyroidectomized rats as determined by a hemolytic assay employing serum deficient in factor $\mathrm{B}$.

\begin{tabular}{lc}
\hline Assay & Factor B activity (\%) \\
\hline 1 & 35.54 \\
2 & 46.05 \\
3 & 70.21 \\
4 & 13.64 \\
5 & 57.65 \\
6 & 62.36 \\
7 & 12.37 \\
8 & 33.95 \\
\hline
\end{tabular}

Data are reported as percent of factor B activity in control animals (sham-operated, normal rats undergoing surgery on the same day). $\mathrm{N}=16$ (from a total of 8 different assays, each using 2 rats).
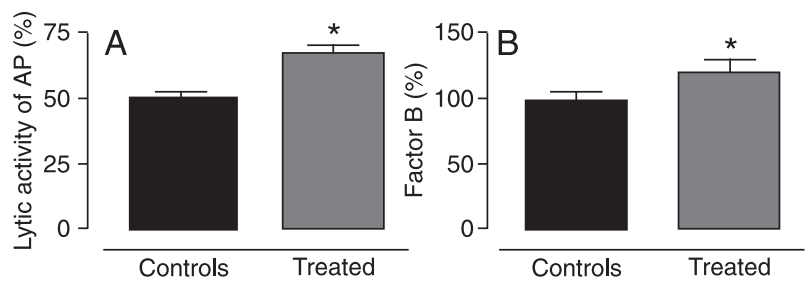

Figure 4. Treatment with propylthiouracil (PTU) alters factor B activity in rats. A, Effect of 16-day PTU treatment $(5 \mathrm{mg} \cdot 200 \mathrm{~g}$ body weight ${ }^{-1} \cdot$ day $^{-1}$ ) on factor $B$ activity, as evaluated by alternative pathway (AP) lytic activity. $B$, Factor $B$ concentration in the sera of rats treated with PTU determined by a radial immunodiffusion assay using rabbit anti-human factor B (Calbiochem). The diameters of the precipitation halos were measured and values are reported as the percentage of the halo diameter calculated from a pool of control rat sera. ${ }^{*} P<0.05$ (ANOVA with the Dunnett test for multiple comparisons).

perthyroidism induced by T3 treatment decreases antibody production (14). Since the reference levels of serum T3 for humans, which were determined using the same method as employed in the present study $(70-210 \mathrm{ng} / \mathrm{dL})$, rats treated with T3 exhibited a significantly higher T3 level ( 700 ng/dL) than untreated rats. Previous analysis of the CS in PTU or thyroidectomy-induced hypothyroidism has shown that the Iytic activity of the AP (but not the CP) was significantly increased in hypothyroid animals compared to control animals (15). Here, we confirm those data and further investigated $\mathrm{AP}$ lytic activity in rats with hyperthyroidism. In agreement with the results of PTU treatment or thyroidectomy, the $\mathrm{CP}$ was not affected by hyperthyroidism under our assay conditions (results not shown). However, the lytic activity of the AP, as evaluated by its capacity to lyse rabbit eryth- rocytes, was dose- and time-dependently reduced. Under these conditions, T4 levels were decreased to undetectable values. These data corroborate our previous observations and show that the thyroid hormone T3 (and its precursor T4) affects the lytic potency of the CS. In an oversimplified view, it is possible that changes in the ability to generate CS fragments as a consequence of thyroid hormone alteration would correspond to an increased or decreased potential to generate an antibody response. Complement activation products generated from the CP interact with cell surface receptors to generate an antibody response (4). The presence of modified-self molecules capable of activating the $A P$ in some of these situations could enhance or even initiate this response. Complement fragments formed during CS activation bind to antigen-antibody complexes (ICs), facilitating IC trapping within germinal centers (12) and maintaining increased local concentrations of the antigen, thus decreasing the threshold for antibody production (1). Therefore, the effects of alterations in thyroid hormone levels on the production of anti-sheep red blood cell antibodies might be explained at least in part, by the effect of thyroid hormones on the CS. In addition, T3 affects DNA synthesis and antibody production by mouse lymphocytes in culture, and it is known that temporarily blocking thyroid function will depress antibody production (24). T3 might regulate $B$ lymphocyte proliferation and antibody production in birds and mammals (6). Hassman et al. (25) reported that the development of an autoimmune response was suppressed in rats treated with a combination of T4 and thyroglobulin plus complete Freund's adjuvant.

In addition to the recognized involvement of the CS in the pathology of autoimmune thyroid disease $(16,26)$, our observations, which were made in the absence of autoimmune processes, might be important for the understanding of the role of CS in triggering the development of these diseases. Factor B activity in the serum of thyroidectomized, PTU-treated or T3-treated rats was also investigated in the present study. Activated factor $\mathrm{B}$ ( $\mathrm{Bb}$ fragment) is part of the membrane AP C3 convertase $(\mathrm{C} 3 \mathrm{bBb})$ that leads to the effective activation of the AP (27). Factor B activity, which we evaluated using a pool of factor B-deficient sera (RB), was also affected by alterations in thyroid hormone levels. Rats treated with PTU or submitted to thyroidectomy showed increased factor B activity, while rats treated with T3 showed decreased factor B activity. An anti-human factor B antibody that cross-reacts with rat factor B allowed us to measure the relative concentration of this protein by radial immunodiffusion in some of the serum samples from rats treated with PTU. In agreement with the increased factor B activity observed in the hemolytic assay employing $\mathrm{RB}$, the results of the immunodiffusion assay showed that the concentration of factor $B$ in sera obtained from hypothyroid rats was increased in comparison to a pool of normal rat sera. Unfortunately, the volume of cross-reacting antibody available was not sufficient to measure the factor 
B concentration in serum samples from thyroidectomized and hyperthyroid rats.

It is important to note that altered factor B activity is not necessarily associated with an altered concentration of factor B. Other components and regulators of complement at the level of factor B activation, such as properdin and factor I, might be affected by the levels of thyroid hormone. We also evaluated the activities of factor $\mathrm{H}$ and $\mathrm{C} 3$ in some serum samples from rats treated with PTU; however, under our assay conditions, we did not observe any alterations in the activity of these components (results not shown).

To our knowledge, these are the first published data showing an effect of thyroid hormones on the activity of

\section{References}

1. Kohl J. The role of complement in danger sensing and transmission. Immunol Res 2006; 34: 157-176.

2. Morgan BP, Marchbank KJ, Longhi MP, Harris CL, Gallimore AM. Complement: central to innate immunity and bridging to adaptive responses. Immunol Lett 2005; 97: 171-179.

3. Barrington R, Zhang M, Fischer M, Carroll MC. The role of complement in inflammation and adaptive immunity. Immunol Rev 2001; 180: 5-15.

4. Prodinger WM, Wurzner R, Erdei A, Dierich MP. Complement. In: Paul WE (Editor), Fundamental Immunology. 4th edn. Philadelphia: Lippincott Ravens Publishers; 1999. $p$ 967-995.

5. Wall JR, Twohig P, Chartier B. Effects of experimental hyperand hypothyroidism on numbers of blood mononuclear cells and immune function in rats and guinea-pigs. $J$ Endocrinol 1981; 91: 61-67.

6. Keast D, Ayre DJ. Antibody regulation in birds by thyroid hormones. Dev Comp Immunol 1980; 4: 323-330.

7. Weetman AP. Autoimmune thyroid disease: propagation and progression. Eur J Endocrinol 2003; 148: 1-9.

8. Weetman AP. Determinants of autoimmune thyroid disease. Nat Immunol 2001; 2: 769-770.

9. Tandon N, Yan SL, Morgan BP, Weetman AP. Expression and function of multiple regulators of complement activation in autoimmune thyroid disease. Immunology 1994; 81: 643-647.

10. Oleesky DA, Ratanachaiyavong S, Ludgate M, Morgan BP, Campbell AK, McGregor AM. Complement component C9 in Graves' disease. Clin Endocrinol 1986; 25: 623-632.

11. Inoue K, Niesen N, Biesecker G, Milgrom F, Albini B. Role of late complement components in experimental autoimmune thyroiditis. Clin Immunol Immunopathol 1993; 66: 1-10.

12. Carroll MC. The complement system in regulation of adaptive immunity. Nat Immunol 2004; 5: 981-986.

13. Duarte CG, Azzolini AE, Assis-Pandochi Al. Effect of the period of treatment with a single dose of propylthiouracil on the antibody response in rats. Int Immunopharmacol 2003; 3: 1419-1427.

14. Bittencourt CS, Azzolini AE, Ferreira DA, Assis-Pandochi Al. Antibody responses in hyperthyroid rats. Int Immunopharmacol 2007; 7: 989-993.

15. Duarte CG, dos Santos GL, Azzolini AE, de Assis Pandochi Al. The effect of the antithyroid drug propylthiouracil on the complement factor B. Thyroid hormones alter the expression, synthesis and activity of factor B. Further studies are necessary to understand how the concentration of thyroid hormones in serum could affect complement proteins.

\section{Acknowledgments}

The authors acknowledge Alcides Silva Pereira and Nadir Mazzucato (Faculdade de Ciências Farmacêuticas de Ribeirão Preto, USP, Ribeirão Preto, SP, Brazil) for technical assistance, Analuiza Souza Costa for the chemiluminescence assays, and CAPES for financial support.

alternative pathway of complement in rats. Int $\mathrm{J}$ Immunopharmacol 2000; 22: 25-33.

16. Wenderfer SE, Soimo K, Wetsel RA, Braun MC. Analysis of $\mathrm{C} 4$ and the $\mathrm{C} 4$ binding protein in the MRL/lpr mouse. Arthritis Res Ther 2007; 9: R114.

17. Ewald RA, Williams JH, Bowden DH. Serum complement in the newborn. An investigation of complement activity in normal infants and in Rh and $A B$ hemolytic disease. Vox Sang 1961; 6: 312-319.

18. Polhill RB Jr, Pruitt KM, Johnston RB Jr. Kinetic assessment of alternative complement pathway activity in a hemolytic system. I. Experimental and mathematical analyses. J Immunol 1978; 121: 363-370.

19. Hamuro J, Hadding U, Bitter-Suermann D. Fragments Ba and $\mathrm{Bb}$ derived from guinea pig factor $\mathrm{B}$ of the properdin system: purification, characterization, and biologic activities. J Immunol 1978; 120: 438-444.

20. Joisel F, Leroux-Nicollet I, Lebreton JP, Fontaine M. A hemoIytic assay for clinical investigation of human C2. J Immunol Methods 1983; 59: 229-235.

21. Mayer MM. Complement and complement fixation. In: Kabat EA, Mayer MM (Editors), Experimental Immunochemistry. 2nd edn. Springfield: Charles C. Thomas, Publisher; 1971. p 133-240.

22. Mancini AM, Zampa GA, Vecchi A, Costanzi G. Histoimmunological techniques for detecting anti-insulin antibodies in human sera. Lancet 1965; 1: 1189-1191.

23. Motulsky HJ. Analyzind data with GraphPad Prism. [Computer program]. San Diego: GrapPad Software Inc.; 1999.

24. Keast $D$, Taylor $K$. The effect of tri-iodothyronine on the phytohaemagglutinin response of $\mathrm{T}$ lymphocytes. Clin Exp Immunol 1982; 47: 217-220.

25. Hassman R, Weetman AP, Gunn C, Stringer BM, WynfordThomas D, Hall R, et al. The effects of hyperthyroidism on experimental autoimmune thyroiditis in the rat. Endocrinology 1985; 116: 1253-1258.

26. Truedsson L, Bengtsson AA, Sturfelt G. Complement deficiencies and systemic lupus erythematosus. Autoimmunity 2007; 40: 560-566.

27. Thurman JM, Holers VM. The central role of the alternative complement pathway in human disease. J Immunol 2006; 176: $1305-1310$. 